\title{
Analyzing the root of regional innovation performance in the European territory
}

\section{Abstract}

Regional innovation performance is an important indicator for decision-making regarding the implementation of policies intended for regional development. However, regional development policies have led economies to very different competitive positions in matters of innovation. To address these issues, this paper aims to identify the variables that most contribute to the positioning of economies in terms of performance innovation in Europe. The data for this study were collected at the Regional Innovation Scoreboard (RIS). We use a quantitative methodology, through a multivariate statistical technique (Discriminant Analysis). The results suggest that specific innovation strategies explain the competitive positioning of economies within each group of countries. It was possible to demonstrate that economies with Leader classification show greater comparative robustness in the variables "SMEs with Product or Process Innovations", "SMEs with Product or Process Innovations", "R\&D Expenditure Public Sector" and "Population with Tertiary Education", constituting an effective instrument of innovation policy. Furthermore, it was possible to show that the economies belonging to the Modest group do not have a competitive advantage in any of the variables under study, thus providing a reflection opportunity for policymakers at this level. The present research identifies which variables are most relevant to the classification considering the regional innovation performance in Leader, Strong, Moderate, and Modest. Several suggestions were given to companies, policy makers, and higher education institutions in the sense that the regions where they operate can improve their innovative performance, which may help to a change in their current classification.

Keywords: Innovation, Regional Innovation Policy, European Innovation Scoreboard, Regional Innovation Scoreboard, Regional Innovation Systems, RIS3, Regional Innovation Performance. 


\section{Introduction}

Innovations are seen as a source to create competitive advantages and even used to compare companies and regions. In the past decades, we have seen

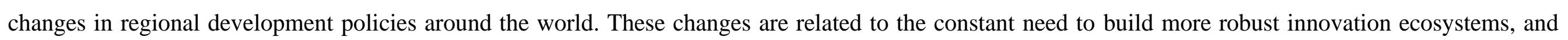
assure they remain globally competitive to respond to the constant new challenges resulted from globalization (Saftescu, Simion, Paul and Mitroi, 2016).

In this context, the regional policy of the European Union (EU) has been changing, supporting the development of innovation in its member states. EU

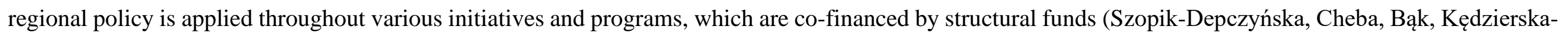

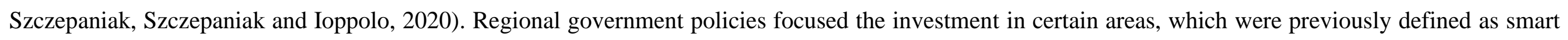

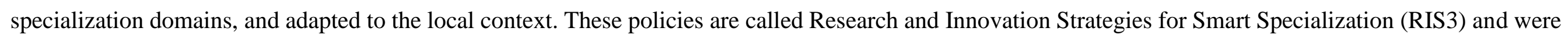

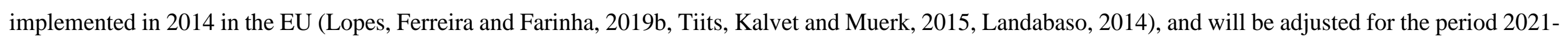

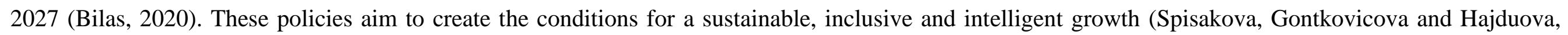
2016).

Such policies have provided relevant progress in science and industry, improving quality and living conditions, implementing greener technologies, and

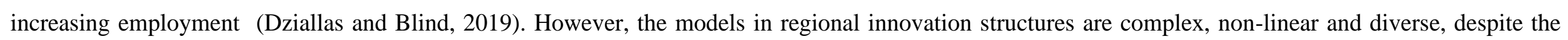

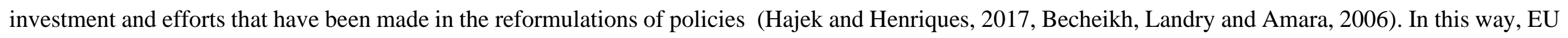

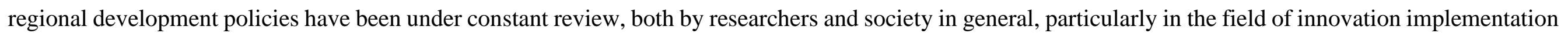

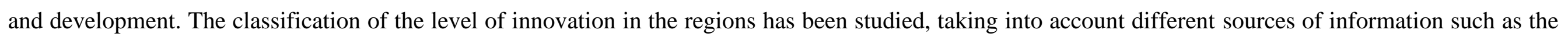

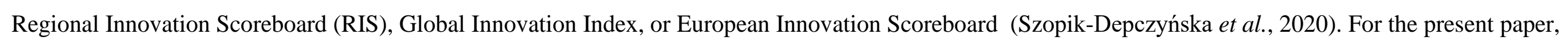

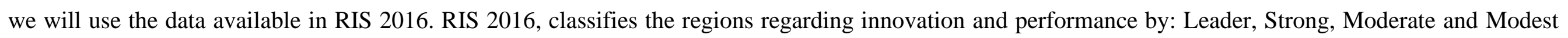
(RIS, 2016, Lopes, Farinha, Ferreira and Silveira, 2018b).

Research on the regions and their innovation have been increasing, with strong divergences, regarding the abilities of public bodies to spend structural

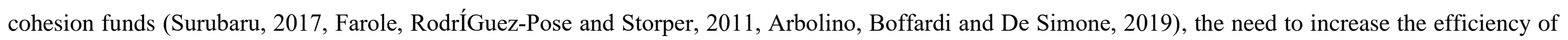

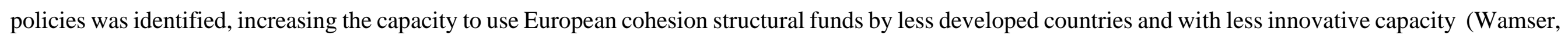

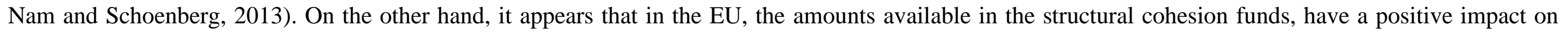

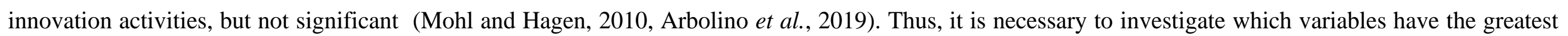

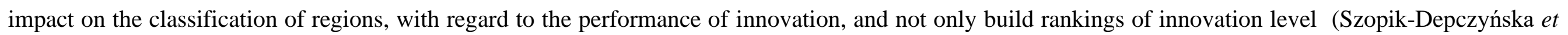

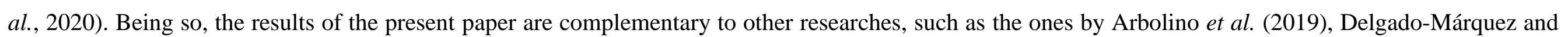

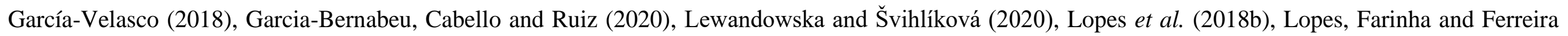
(2019a), Saftescu et al. (2016) and Szopik-Depczyńska et al. (2020).

In this context, the objective of the present paper is to identify which of the variables under study, shown in table 1 , allow to significantly discriminate

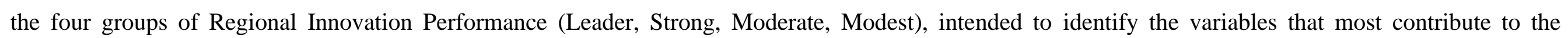




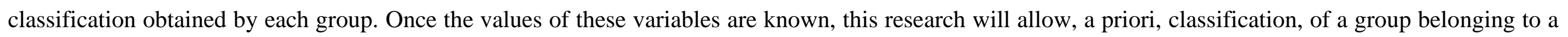
region not yet classified.

We anticipate that the results of this research will be a valuable source of information for regional stakeholders. The regions will be able to see which

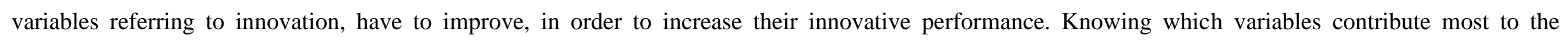

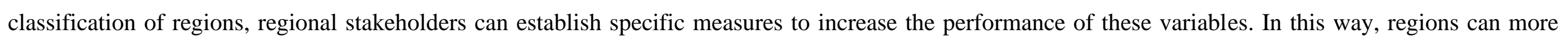

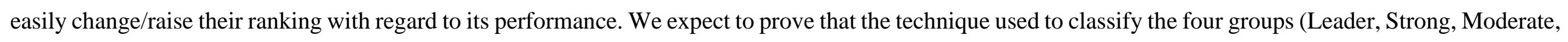
Modest) regarding the Regional Innovation Performance is valid.

This paper commences with the introduction, where the theme under study is outlined. In the second part, an extensive literature review about RIS3 and

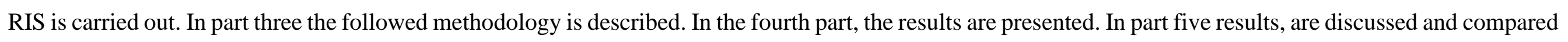

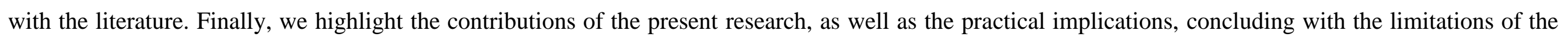
research and future lines of investigation.

\section{Literature Review}

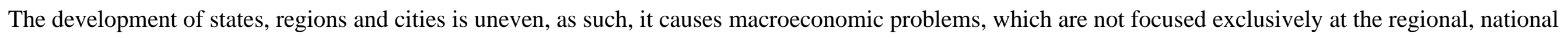

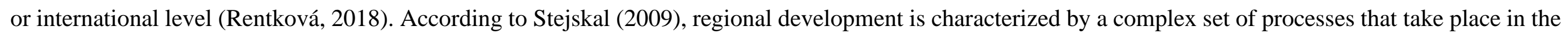

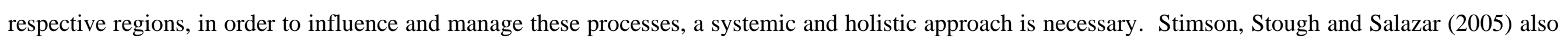

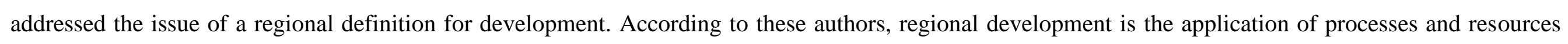

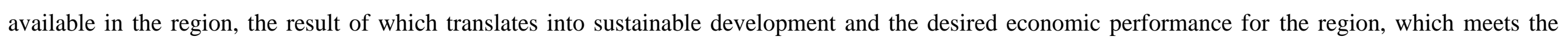
expectations of people and organizations.

Thus, the analysis of regional disparities is a fundamental issue, when it is intended to guarantee regional development. The term regional disparities

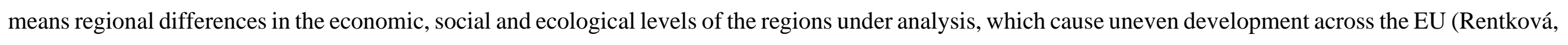

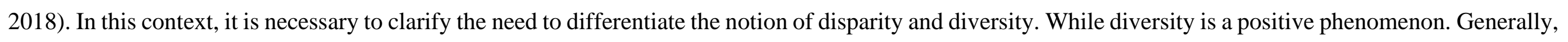

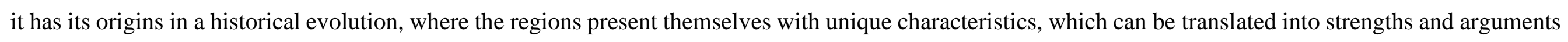

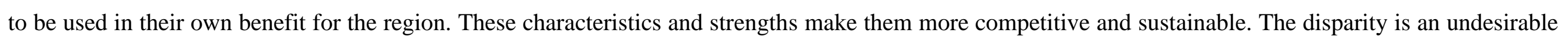

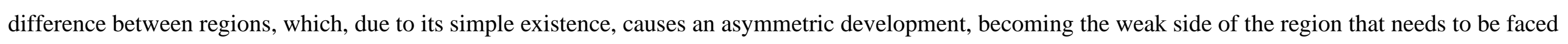

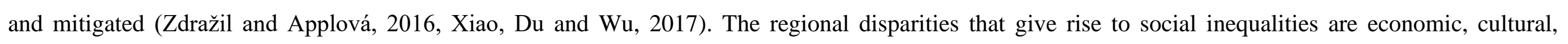
infrastructural, of living conditions, and which, ultimately, can provoke regional polarization.

Aware of this reality, the EU supports the development of its regions through a regional development policy, with a view to mitigating these disparities,

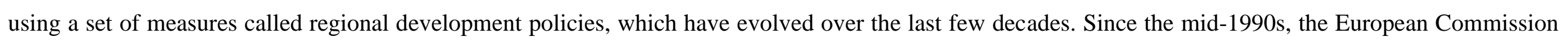

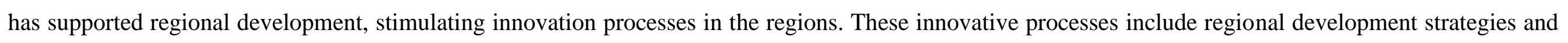




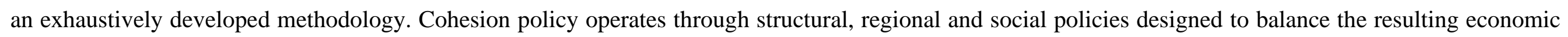
and social disparities in EU regions.

Several authors have tackled the subject of regional innovation systems (Lopes and Franco, 2019, Cooke, Uranga and Etxebarria, 1997, Asheim and Coenen, 2005, Cooke, 1992, Leydesdorff and Fritsch, 2006). The Regional Innovation Systems reflects an interactive learning process capable of very quickly producing evidence about institutional reactions (Cooke, 1992). A system is defined as a series of discrete elements, as well as the relationships between them (Georghiou, 1993, Lundvall, 2007). Regional innovation systems consist of interactive learning from formal institutions, public or private, which have common interests (Doloreux, 2011, Fagerberg, 2003). A regional innovation system can be defined as a system of innovative networks and institutions, whose purpose is to develop the innovative capacity of companies in a region (Lopes and Franco, 2019).

Recently, smart specialization and RIS3 has emerged. The smart specialization consists of the promotion of efficient use and the enhancement of the real effects of public investment, in the view of economic growth and prosperity of countries and regions (McCann and Ortega-Argilés, 2013, McCann and OrtegaArgiles, 2015). RIS3 derives from the EC proposal, aiming to regulate the structural financing program for the period 2014-2020 and 2021-2027. These regulations include innovation strategies for smart specialization (Tiits et al., 2015). RIS3 is the local-based integrated economic transformation political agenda, that starts with the identification of the specific characteristics and assets of each region, enabling a process participated by all interested parties, to establish a vision of a sustainable future for the territory (Panciroli, Santangelo and Tondelli, 2020). Consequently, they are a response to the complex development challenges on policy adaptation to the regional context (Lopes et al., 2019b). RIS3 channels economic development efforts and investments to the relative gains in each region, exploring their respective economic opportunities and emerging trends, and taking measures to enhance their economic growth. RIS3 ensures that the combination of policies and the available instruments in a given regional environment is effective, whether through grants, loans and other type of support, proving to be effective in achieving the desired goals (Costa, 2020, Iammarino, 2018). In this sense, it is valid to affirm that RIS3 represents the evolution of the RIS concept, which encompasses the concept of intelligent specialization.

According to the objectives of the research announced earlier, this paper starts from the idea that the competitiveness of European regions is necessarily linked to regional innovation systems, and that a good knowledge of the relationship between innovation and competitiveness is essential to assess its effects and economic policies capable of increasing the level of competitiveness and growth of European regions (Sabatino and Talamo, 2017, Hajek and Henriques, 2017). Therefore, as industries and companies can base their competitiveness on indicators such as innovation, at the territorial level, the regions are also positioned amongst themselves, which characterizes them as more or less innovative. Ideally, the performance of regional innovation should be measured using the complete measurement table of the Regional Innovation Scoreboard (RIS), that is, using regional data for the same indicators applied to measure innovation performance at the country level. RIS (2016), classifies the regions in terms of their Regional Innovation Performance as: Leader, Strong, Moderate, Modest (Lopes, Farinha, Ferreira and Ferreira, 2018a).

RIS (2016), encompasses the following 12 variables (table 1): i) Population with Tertiary Education (\%); ii) R\&D expenditure in the public sector (\%); iii) R\&D expenditure in the business sector (\%); iv) Non-R\&D SME innovation expenditures (\%); v) SME innovating in-house (\%); vi) Innovative SMEs collaborating with others (\%); vii) EPO patent applications (per billion GDP); viii) SME with product or process innovations (\%); ix) SME with marketing or organizational innovations (\%); x) Employment in medium-high/high tech manufacturing and knowledge-intensive services (\%); xi) Exports of medium- 
high/high technology-intensive manufacturing (\%); and xii) Sales of new-to-market and new-to-firm innovation by SMEs (\%) (Lopes et al., 2018b, Lopes et al., 2019a). Table 1. presents the definitions of each variable under study.

Table 1 - Regional innovation scoreboard 2016 - variables

\begin{tabular}{|c|c|}
\hline Regional Innovation Scoreboard - Indicators & Definition \\
\hline Population with Tertiary Education & $\begin{array}{l}\text { Corresponds to the number of people in the age group with some type of post-secondary education. The indicator focuses on the population aged } \\
\text { between } 30 \text { and } 34 \text {. }\end{array}$ \\
\hline $\mathrm{R} \& \mathrm{D}$ expenditure in the public sector & $\begin{array}{l}\text { It represents expenditure on research and development }(\mathrm{R} \& \mathrm{D}) \text { which is one of the main drivers of economic growth in a knowledge-based } \\
\text { economy. }\end{array}$ \\
\hline $\mathrm{R} \& \mathrm{D}$ expenditure in the business sector & It captures the formal creation of new knowledge within companies. \\
\hline Non-R\&D innovation expenditures in SMEs & Quantifies non-R\&D related innovation expenditures as a percentage of total turnover. \\
\hline SMEs innovating in-house & $\begin{array}{l}\text { It is based on the introduction of new products or production processes in SMEs, whether they are products or production processes that have } \\
\text { been significantly improved and that companies have innovated internally. }\end{array}$ \\
\hline Innovative SMEs collaborating with others & Measures the degree of participation of SMEs in cooperation for innovation. \\
\hline EPO patent applications & Measures the number of patent applications at the European Patent Office. \\
\hline SMEs with product or process innovations & $\begin{array}{l}\text { Indicates technological innovation, which is measured by the introduction of new products (goods or services) and processes, which are a key } \\
\text { ingredient for innovation in manufacturing activities. }\end{array}$ \\
\hline SMEs with marketing or organizational innovations & It captures the extent to which SMEs innovate through non-technological innovation. \\
\hline $\begin{array}{l}\text { Employment in medium-high/high tech manufacturing and } \\
\text { knowledge-intensive services }\end{array}$ & Indicates the share of employment in the high-tech manufacturing sectors. \\
\hline $\begin{array}{l}\text { Exports of medium-high/high technology-intensive } \\
\text { manufacturing }\end{array}$ & Measures technological competitiveness in a region, that is, its ability to commercialize $R \& D$ and innovation results in international markets. \\
\hline Sales of new-to-market and new-to-firm innovation in SMEs & Measures the turnover of new or significantly improved products for the company as a percentage of the total turnover. \\
\hline
\end{tabular}

\section{Methodology}

In the present research, the followed methodology is quantitative. The quantitative methodology explains phenomena, based on numerical data which is analyzed using mathematical methods, and mainly statistics (Creswell, 1994, Mills and Gay, 2019). The present research aims to identify which of the variables allow to significantly discriminate the four groups regarding the Regional Innovation Performance (Leader, Strong, Moderate, Modest), catalogued in RIS (2016). Thus, this methodology is the most appropriate because, as a rule, it requires large representative samples, selected in order to generalize the results achieved, prediction of cause and effect relationships through deductive reasoning (Yilmaz, 2013).

The data for the present research was collected at the Regional Innovation Scoreboard (RIS) 2016 (https://op.europa.eu/s/oofu) on June 26 ${ }^{\text {th }}$, 2018. The collected data was inputted and analyzed using the SPSS (version 26). RIS (2016) contemplates a comparative assessment, regarding the performance of innovation systems in the 22 EU Member States, which is divided into 214 regions, including Serbia, Switzerland and Norway. RIS (2016), also includes the countries of Malta, Cyprus, Latvia, Estonia, Luxembourg and Lithuania. RIS (2016) ranks 53 regions in Leader, 60 regions in Strong, 85 regions in Moderate, and 22 regions in Modest.

According to Marôco (2018), Discriminant Analysis is a multivariate statistical technique whose objectives are: (i) identification of the variables that best differentiate or "discriminate" between two or more structurally different and mutually exclusive groups; (ii) the use of these variables to create a discriminant function that sparingly represents differences between groups; and (iii) the use of this function to classify new individuals in groups a priori. Being so, for this research, Stepwise Discriminant Analysis was used with Wilks $\Lambda$ method to identify which of the variables under study allow to significantly discriminate the four groups of Regional Innovation Performance (Leader, Strong, Moderate, Modest). 
The normality assumptions of each group were tested, respectively with the Kolmogorov-Smirnov test in the group's Leader (N=53), Strong (N=60) and Moderate ( $\mathrm{N}=85)$ and Shapiro-Wilk test in Modest group ( $\mathrm{N}=22)$. According to these tests, all variables have a normal distribution in each of the Regional Innovation Performance groups $(\mathrm{p}<0,05)$ except for the variable Non- $R \& D$ Innovation Expenditures in Leader group $(\mathrm{KS}=0.148 ; \mathrm{p}=0,005)$ and in Strong group (KS=0.13; $\mathrm{p}=0,01)$, of variable SMEs Innovating In-House in Leader group (KS=0.139; $\mathrm{p}=0,01)$, in Strong group $(\mathrm{KS}=0.124 ; \mathrm{p}=0,02)$, in Moderate group $(\mathrm{KS}=0.128 ; \mathrm{p}=0,001)$ and in Modest group ( $\mathrm{SW}=0.842 ; \mathrm{p}=0,003)$, of variable Innovative SMEs Collaborating with Others in Leader group (KS=0.128; $\mathrm{p}=0,03)$ and in Modest group ( $\mathrm{SW}=0.820 ; \mathrm{p}=0,001)$ and variable Sales of New-To-market and New-To-Firm Innovations in Leader group (KS=0.260; $\mathrm{p}=0,00)$, in $\mathrm{Strong}$ group $(\mathrm{KS}=0.188 ; \mathrm{p}=0,00)$ and in Moderate group $(\mathrm{KS}=0.121 ; \mathrm{p}=0,004)$. This is, because Discriminant Analysis is robust to variations from normality (Marôco, 2018) these variables were used in the analysis.

The assumption of homogeneity of the variance-covariance matrices was tested with the Box M test, which proved to be valid ( $p=0.365)$, accepting the hypothesis of homogeneity of the variance-covariance matrices.

Finally, a classificatory analysis with cross-validation was used to obtain classification functions to allow to predict in which Regional Innovation Performance group new case studies could be classified.

\section{Results}

The focus on regional innovation policies is seen as a source of competitive advantage for economies (Hajek and Henriques, 2017). Thus, there is an urgent need to make innovation ecosystems more robust, capable of asserting themselves at a competitive global level (Saftescu et al., 2016). In this alignment, Research and Innovation Strategies for Smart Specialization (RIS3) have been achieving political popularity, especially in Europe (Lopes et al., 2019b, Tiits et al., 2015). In the EU, it appears that the structural cohesion funds have a positive impact on innovation activities, with the need to increase the capacity to use these funds, by less developed countries and with less innovative capacity (Arbolino et al., 2019, Mohl and Hagen, 2010, Wamser et al., 2013).

For such, the behavior of the variables of RIS 2016 was analyzed, to study the agglomeration of countries by innovative performance groups: i) Population with Tertiary Education (\%); ii) R\&D expenditure in the public sector (\%); iii) R\&D expenditure in the business sector (\%); iv) Non-R \& D SME innovation expenditures (\%); v) SME innovating in-house (\%); vi) Innovative SMEs collaborating with others (\%); vii) EPO patent applications (per billion GDP); viii) SME with product or process innovations (\%); ix) SME with marketing or organizational innovations (\%); x) Employment in medium-high / high tech manufacturing and knowledge-intensive services (\%); xi) Exports of medium-high / high technology-intensive manufacturing (\%); and xii) Sales of new-tomarket and new-to-firm innovation by SMEs (\%) (Lopes et al., 2018b, Lopes et al., 2019a). Thus, Analysis of Variance or ANOVA was used to compare the distribution of three or more groups in independent samples. In this perspective, the individual ANOVA for each of the independent variables considered shows that only the variable Non-R \& D Innovation Expenditures cannot be considered as discriminant ( $p=0.98)$ for the usual levels $(\alpha=0.05)$ (see table 2).

Table 2 - Tests of Equality of Group Means

\begin{tabular}{|c|c|c|c|c|c|}
\hline \multicolumn{6}{|c|}{ Tests of Equality of Group Means } \\
\hline & Wilks' Lambda & $\mathrm{F}$ & df1 & df2 & Sig. \\
\hline Population with Tertiary Education & ,719 & 28,091 & 3 & 216 & ,000 \\
\hline
\end{tabular}




\begin{tabular}{|c|c|c|c|c|c|}
\hline R\&D Expenditure Public Sector & ,707 & 29,845 & 3 & 216 &, 000 \\
\hline R\&D Expenditure Business Sector &, 455 & 86,080 & 3 & 216 &, 000 \\
\hline Non-R\&D Innovation Expenditures & ,971 & 2,128 & 3 & 216 & ,098 \\
\hline SMEs Innovating In-House &, 540 & 61,424 & 3 & 216 &, 000 \\
\hline Innovative SMEs Collaborating with Others &, 566 & 55,239 & 3 & 216 &, 000 \\
\hline EPO Patent Applications &, 377 & 118,984 & 3 & 216 &, 000 \\
\hline SMEs With Product or Process Innovations & ,466 & 82,577 & 3 & 216 &, 000 \\
\hline SMEs with Marketing or Organizational Innovations & ,489 & 75,150 & 3 & 216 &, 000 \\
\hline Employment Medium-High/ High Tech Manufacturing \&amp; Knowledge Intensive Services &, 754 & 23,489 & 3 & 216 &, 000 \\
\hline Exports in Medium-High/ High Tech Manufacturing & ,921 & 6,212 & 3 & 216 &, 000 \\
\hline Sales of New-To-market and New-To-Firm Innovations & ,697 & 31,295 & 3 & 216 &, 000 \\
\hline
\end{tabular}

In each step of the Stepwise method, the selected variable is the one that minimizes the value of $\Lambda$ of Wilks, that is, the one for which the greatest differences between groups occur. The process is repeated until there are no significant differences in $\Lambda$.

The Stepwise Discriminant Analysis extracted 3 discriminating functions, retaining Population with Tertiary Education, R\&D Expenditure Public Sector, R\&D Expenditure Business Sector, SMEs Innovating In-House, Innovative SMEs Collaborating with Others, EPO Patent Applications, SMEs with Product or as statistically significant. Process Innovations, SMEs with Marketing or Organizational Innovations, Exports in Medium-High / High Tech Manufacturing and Sales of New-To-market and New-To-Firm Innovations.

Table 3 below shows the standardized coefficients of these variables in the discriminant functions.

Table 3 - Standardized Canonical Discriminant Function Coefficients

\begin{tabular}{|c|c|c|c|}
\hline \multicolumn{4}{|c|}{ Standardized Canonical Discriminant Function Coefficients } \\
\hline & \multicolumn{3}{|c|}{ Coefficients in discriminant functions } \\
\hline & 1 & 2 & 3 \\
\hline Population with Tertiary Education & ,277 &,- 200 &,- 586 \\
\hline R\&D Expenditure Public Sector & ,234 &, 452 &,- 081 \\
\hline R\&D Expenditure Business Sector & ,096 & ,624 &,- 041 \\
\hline SMES Innovating In-House &,- 149 &,- 432 & 1,730 \\
\hline Innovative SMEs Collaborating with Others &, 587 &,- 707 &, 502 \\
\hline EPO Patent Applications & ,636 &,- 555 &,- 346 \\
\hline SMEs with Product or Process Innovations & ,306 &, 823 & $-1,165$ \\
\hline SMEs with Marketing or Organizational Innovations & ,269 &,- 406 &,- 088 \\
\hline Exports in Medium-High/High Tech Manufacturing & ,263 &,- 215 & ,235 \\
\hline Sales of New-To-market and New-To-Firm Innovations &, 076 & 824 & ,245 \\
\hline
\end{tabular}


Function 1 is essentially defined by the EPO Patent Applications and Innovative SMEs Collaborating with other variables, positively discriminates the four groups $\left(\Lambda=0.091 ; \chi^{\wedge} 2=507.53 ; p=0.000\right)$ and explains $89.1 \%$ of the variability between the groups $(\lambda=5,272)$.

Function 2 is essentially defined by the variables Sales of New-To-market and New-To-Firm Innovations, SMEs with Product or Process Innovations and R\&D Expenditure Business Sector, positively discriminates against the 4 groups $\left(\Lambda=0.572 ; \chi^{\wedge} 2=118.28 ; \mathrm{p}=0.000\right)$ and explains $6.1 \%$ of the variability between groups $(\lambda=0.364)$.

Function 3 is essentially defined by the variables SMEs Innovating In-House and Innovative SMEs Collaborating with Others, positively discriminates the 4 groups $\left(\Lambda=0.781 ; \chi^{\wedge} 2=52.49 ; p=0.000\right)$ and explains $4.7 \%$ of the variability between groups $(\lambda=0.281)$.

Figure 1 illustrates the positioning of each country in the territorial map of the scores of the first two discriminating functions and the centroids of each of the four Regional Innovation Performance groups (Leader, Strong, Moderate, Modest).

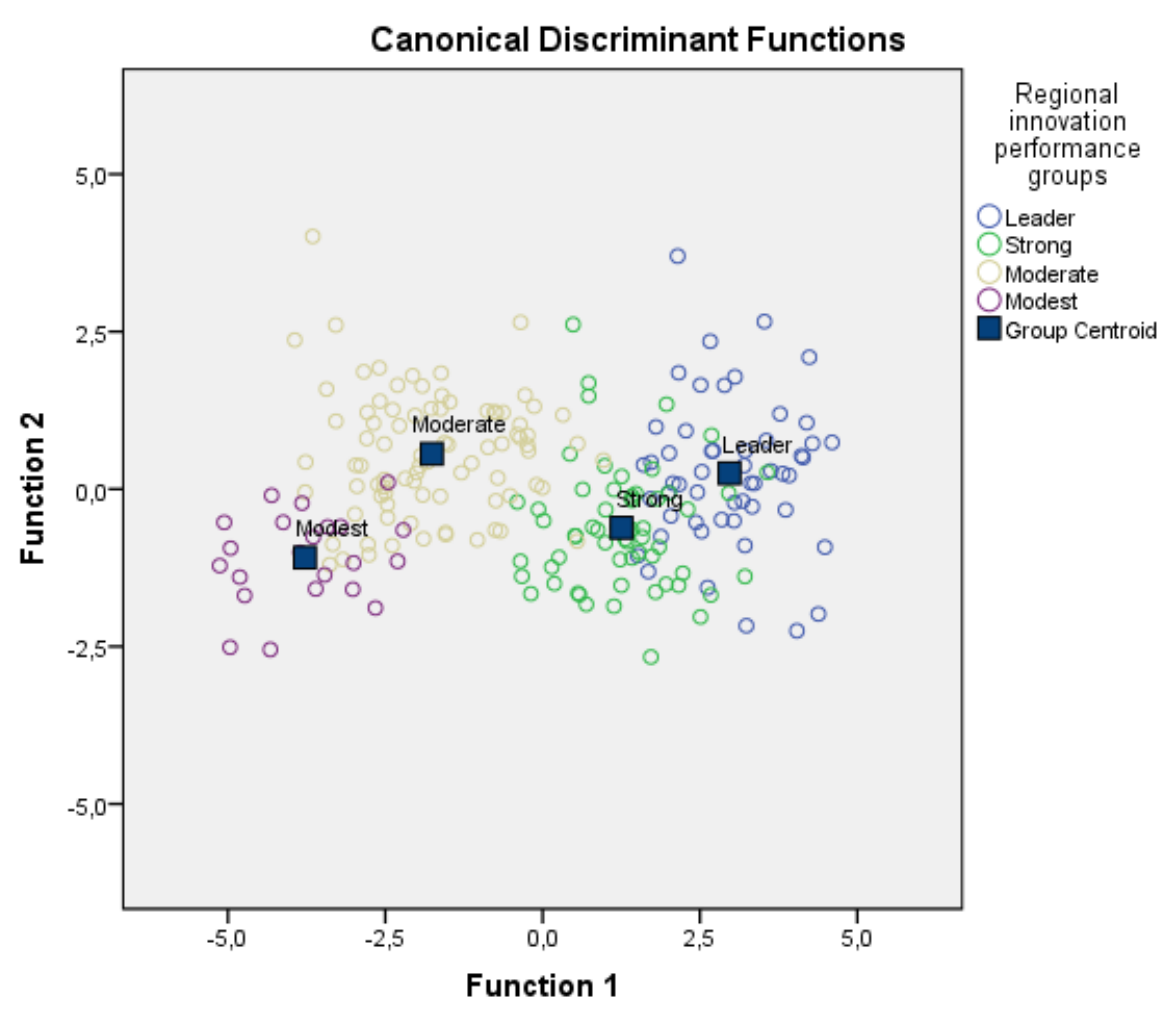

Figure 1 - Canonical discriminant functions

Table 4 exhibits the coefficients of the classification functions defined for each of the Regional Innovation Performance groups. The competitiveness of European regions is necessarily linked to regional innovation systems and a good knowledge of the relationship between innovation and competitiveness is essential to assess the effects of public policies on increasing the competitiveness and growth of the European regions (Hajek and Henriques, 2017, Sabatino and Talamo, 2017). According to RIS (2016), economies are grouped into four groups, depending on their level of performance in terms of regional innovation (Leader, Strong, Moderate, Modest) (Lopes et al., 2018b). 
These functions serve only as an a priori classification for new individuals in the groups, without any discriminative interpretation. Depending on the values of the variables of a new subject and its substitution in the respective equation, these coefficients allow the determination of the group to which the individual belongs as being the one whose classification function allows to obtain a higher score.

Table 4 - Classification Function Coefficients

\begin{tabular}{|c|c|c|c|c|}
\hline \multicolumn{5}{|c|}{ Classification Function Coefficients } \\
\hline & \multicolumn{4}{|c|}{ Regional innovation performance groups } \\
\hline & Leader & Strong & Moderate & Modest \\
\hline Population with Tertiary Education & 31,299 & 25,059 & 19,936 & 22,450 \\
\hline R\&D Expenditure Public Sector & 27,956 & 21,929 & 20,973 & 13,312 \\
\hline R\&D Expenditure Business Sector & $-5,340$ & $-11,111$ & $-7,577$ & $-16,607$ \\
\hline SMEs Innovating In-House & 4,865 & 24,284 & 18,607 & 12,468 \\
\hline Innovative SMEs Collaborating with Others & 25,270 & 26,556 & 8,757 & 5,213 \\
\hline EPO Patent Applications & 38,520 & 29,834 & 9,285 & 9,310 \\
\hline SMEs with Product or Process Innovations & 33,106 & 11,907 & 16,236 & 10,437 \\
\hline SMEs with Marketing or Organizational Innovations & 4,776 & 3,100 & $-6,635$ & $-4,924$ \\
\hline Exports in Medium-High/High Tech Manufacturing & 28,070 & 28,138 & 22,855 & 20,867 \\
\hline Sales of New-To-market and New-To-Firm Innovations & 30,933 & 26,279 & 31,638 & 16,651 \\
\hline (Constant) & $-63,613$ & $-46,606$ & $-28,149$ & $-16,241$ \\
\hline
\end{tabular}

Through the analysis of function 1 (which is the most discriminating), table 5 shows, that the average of this function assumes the highest value in the Leader group and that this average value decreases when the Leader classification is passed for each of the others ( Strong, Moderate and Modest). When analyzing table 4 , it is possible to see which variables have greater weight and, therefore, discriminate more in the classification of each group.

For the Leader classification, and in descending order, are the variables EPO Patent Applications, SMEs With Product or Process Innovations, Population with Tertiary Education, Sales of New-To-market and New-To-Firm Innovations, Exports in Medium-High / High Tech Manufacturing, R\&D Expenditure Public Sector and Innovative SMEs Collaborating with Others have the greatest weight in the classification obtained. In this group and the SMEs Innovating InHouse variable, the lowest values of all groups (Strong, Moderate, Modest) are obtained.

For the Strong classification and, in descending order, are the variables EPO Patent Applications, Exports in Medium-High / High Tech Manufacturing, SMEs Collaborating with Others, Sales of New-To-market and New-To-Firm Innovations, Population with Tertiary Education, SMEs Innovating In-House, R\&D Expenditure Public Sector and SMEs with Product or Process Innovations have the greatest weight in the classification obtained. In this group and compared to the other variables of the Leader Group, there is a greater relative weight of the variables SMEs Innovating In-House and Innovative SMEs Collaborating with Others, a very similar weight in the variable Exports in Medium-High / High Tech Manufacturing and a lower relative weight in all other variables, although not far from the Leader classification values. 
In the Moderate classification, overall, the weights of each of the variables are lower than those of the Strong and Leader groups. The variables with the greatest weight are Sales of New-To-market and New-To-Firm Innovations (which obtain even the highest value of all groups), Exports in Medium-High / High Tech Manufacturing, R\&D Expenditure Public Sector and Population with Tertiary Education (which obtains the lowest value of all groups).

In the Modest classification, in general, the weights of each of the variables are the lowest of all groups, obtaining, nevertheless, better scores than the Moderate classification in the variable Population with Tertiary Education and very approximate values in the variable's EPO Patent Applications and Exports in Medium-High / High Tech Manufacturing.

The pace of development in the regions is uneven and causes macroeconomic problems, according to a complex set of processes related to each territory or country (Rentková, 2018, Stejskal, 2009). Generally, we can affirm that Leader-rated economies show greater comparative robustness in the variables "SMEs With Product or Process Innovations", "SMEs with Product or Process Innovations", "R\&D Expenditure Public Sector" and "Population with Tertiary Education "; presenting a worse performance in the variable "SMEs Innovating In-House". The economies classified in the Strong group, stand out as positive in the variables "Exports in Medium-High / High Tech Manufacturing”, "Innovative SMEs Collaborating with Others" and "SMEs Innovating In-House”, presenting a worse performance at the level of the variable "SMEs with Marketing or Organizational Innovations". The group of economies classified as Moderate, have a competitive advantage in the variable "Sales of New-To-market and New-To-Firm Innovations", losing in comparison with the other groups, in the variables "EPO Patent Applications" and "Population with Tertiary Education". Finally, the economies belonging to the Modest group do not have a competitive advantage in any of the variables, presenting even worse comparative performance in the variables "R\&D Expenditure Public Sector", "Innovative SMEs Collaborating with Others", "SMEs with Product or Process Innovations", "Exports in Medium-High / High Tech Manufacturing” and "Sales of New-To-market and New-To-Firm Innovations".

Table 5 - Functions at Group Centroids

\begin{tabular}{|l|c|c|c|}
\hline \multicolumn{4}{|c|}{ Functions at Group Centroids } \\
\hline Regional innovation & \multicolumn{3}{|c|}{ Function } \\
\hline performance groups & 1 & 2 & 3 \\
\hline Leader & 4.369 & .202 & -.580 \\
\hline Strong & 1.820 & -.505 & .645 \\
\hline Moderate & -2.691 & .531 & .115 \\
\hline Modest & -5.091 & -1.161 & -.805 \\
\hline Unstandardized canonical discriminant functions evaluated at group \\
means
\end{tabular}

Comparing the Regional Innovation Performance groups originally assigned with those determined by the use of the classification function coefficients, the percentage of countries correctly classified in each group was $83.6 \%$. This means that with the discriminant functions obtained and without knowing the classifications of the various groups, we would be able to classify $83.6 \%$ of them, which represents a high value. The correct classifications by group are, respectively, Leader $-84.5 \%$, Strong - $85 \%$; Moderate $-78.8 \%$ and Modest $-95.5 \%$, as shown in table 6 . 
Table 6 - Classification Results

\begin{tabular}{|c|c|c|c|c|c|c|c|}
\hline \multicolumn{8}{|c|}{ Classification Results $^{\mathrm{a}}$} \\
\hline & & \multirow[t]{2}{*}{ Regional innovation performance groups } & \multicolumn{4}{|c|}{ Predicted Group Membership } & \multirow[t]{2}{*}{ Total } \\
\hline & & & Leader & Strong & Moderate & Modest & \\
\hline \multirow[t]{8}{*}{ Original } & \multirow[t]{4}{*}{ Count } & Leader & 45 & 8 & 0 & 0 & 53 \\
\hline & & Strong & 7 & 51 & 2 & 0 & 60 \\
\hline & & Moderate & 0 & 6 & 67 & 12 & 85 \\
\hline & & Modest & 0 & 0 & 1 & 21 & 22 \\
\hline & \multirow[t]{4}{*}{$\%$} & Leader & 84,9 & 15,1 & 0 & 0 & 100,0 \\
\hline & & Strong & 11,7 & 85,0 & 3,3 &, 0 & 100,0 \\
\hline & & Moderate &, 0 & 7,1 & 78,8 & 14,1 & 100,0 \\
\hline & & Modest & 0 & 0 & 4,5 & 95,5 & 100,0 \\
\hline
\end{tabular}

a. $83,6 \%$ of original grouped cases correctly classified.

As we can see in table 7, the variables that have a greater weight in the classification of regions in Leader are: 1) SMEs with Product or Process

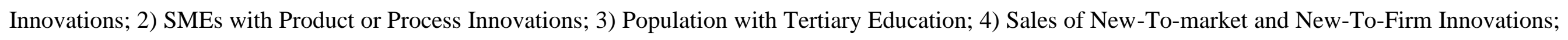

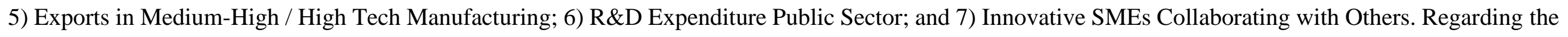

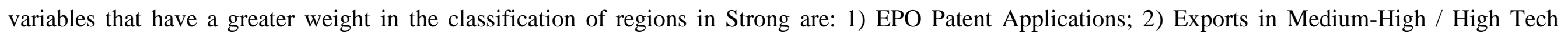

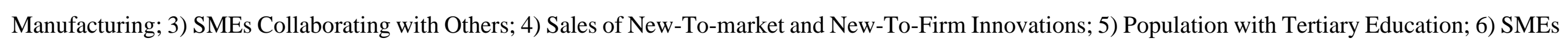

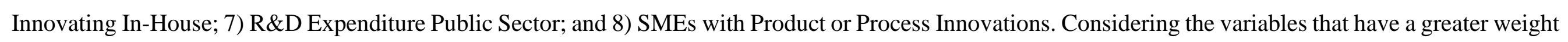

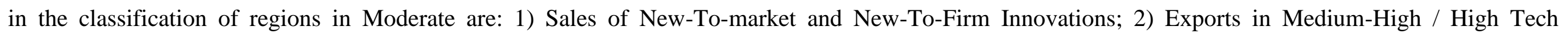

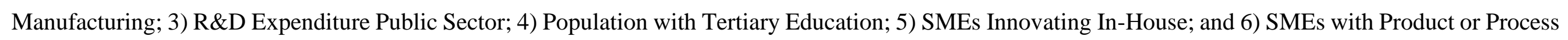

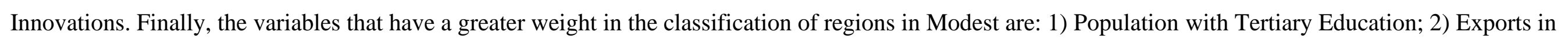

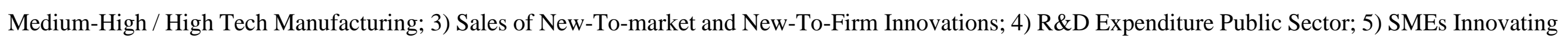
In-House; and 6) SMEs with Product or Process Innovations.

Table 7 - Regional innovation performance groups - Variables that most contributed to the obtained classification

\begin{tabular}{|c|c|c|c|c|}
\hline & Leader & Strong & Moderate & Modest \\
\hline $1^{\circ}$ & EPO Patent Applications & EPO Patent Applications & Sales of New-To-market and New-To-Firm Innovations & $\begin{array}{l}\text { Population with Tertiary } \\
\text { Education }\end{array}$ \\
\hline $2^{\circ}$ & SMEs with Product or Process Innovations & Exports in Medium-High/ High Tech Manufacturing & Exports in Medium-High/ High Tech Manufacturing & $\begin{array}{l}\text { Exports in Medium-High/ } \\
\text { High Tech Manufacturing }\end{array}$ \\
\hline $3^{\circ}$ & Population with Tertiary Education & Innovative SMEs Collaborating with Others & R\&D Expenditure Public Sector & $\begin{array}{l}\text { Sales of New-To-market } \\
\text { and New-To-Firm } \\
\text { Innovations }\end{array}$ \\
\hline $4^{\circ}$ & Sales of New-To-market and New-To-Firm Innovations & Sales of New-To-market and New-To-Firm Innovations & Population with Tertiary Education & $\begin{array}{l}\text { R\&D Expenditure Public } \\
\text { Sector }\end{array}$ \\
\hline
\end{tabular}




\begin{tabular}{|c|c|c|c|c|}
\hline $5^{\circ}$ & Exports in Medium-High/ High Tech Manufacturing & Population with Tertiary Education & SMEs Innovating In-House & $\begin{array}{l}\text { SMEs Innovating In- } \\
\text { House }\end{array}$ \\
\hline $6^{\circ}$ & R\&D Expenditure Public Sector & SMEs Innovating In-House & SMEs with Product or Process Innovations & $\begin{array}{l}\text { SMEs with Product or } \\
\text { Process Innovations }\end{array}$ \\
\hline $7^{\circ}$ & Innovative SMEs Collaborating with Others & R\&D Expenditure Public Sector & EPO Patent Applications & EPO Patent Applications \\
\hline $8^{\circ}$ & SMEs Innovating In-House & SMEs with Product or Process Innovations & Innovative SMEs Collaborating with Others & $\begin{array}{l}\text { Innovative SMEs } \\
\text { Collaborating with Others }\end{array}$ \\
\hline $9^{\circ}$ & SMEs with Marketing or Organizational Innovations & SMEs with Marketing or Organizational Innovations & SMEs with Marketing or Organizational Innovations & $\begin{array}{l}\text { SMEs with Marketing or } \\
\text { Organizational } \\
\text { Innovations }\end{array}$ \\
\hline $10^{\circ}$ & R\&D Expenditure Business Sector & R\&D Expenditure Business Sector & R\&D Expenditure Business Sector & $\begin{array}{l}\text { R\&D Expenditure } \\
\text { Business Sector }\end{array}$ \\
\hline
\end{tabular}

\section{Final Remarks}

\subsection{Contributions and Practical Implications}

The Regional Innovation Scoreboard (RIS) includes a broad comparative analysis, with regard to the performance of innovation in different regions/countries of the EU, as well as other regions/countries neighboring the EU. Specifically, it shows the impacts on the economy resulting from innovation activities (Kijek and Matras-Bolibok, 2019). RIS classifies countries/regions into four distinctive groups of innovation performance: Leader, Strong, Moderate, Modest (RIS, 2016). Thus, the present paper aims to identify which of the variables that allow to significantly discriminate the four groups regarding the Regional Innovation Performance (Leader, Strong, Moderate, Modest).

With the present research, we concluded that by comparing the Regional Innovation Performance groups originally assigned with those determined by the use of the classification function coefficients, the percentage of countries correctly classified in each group was $83.6 \%$. This points out that with the discriminant functions achieved and without knowing the classifications of the various groups, we would be able to classify $83.6 \%$ of them, which represents a high value. We also concluded that the correct classifications by group, regarding Regional Innovation Performance, are $84.5 \%$ in Leader regions, $85 \%$ in Strong regions, $78.8 \%$ in Moderate regions, and $95.5 \%$ in Modest regions. The statistical results of the present research also suggest that the technique used to classify the four groups (Leader, Strong, Moderate, Modest) regarding the Regional Innovation Performance is valid and robust. In Table 7 , we summarize the results obtained in the present research, clearly identifying which variables contributed the most to the classification obtained by each group. They are ordered from the most significant to the least significant.

Having identified the variables that have the greater weight in the classification of regions, Leader, Strong, Moderate and Modest, it is important to postulate some suggestions for policy makers, companies, and universities to take into consideration, in order to improve the innovation performance of regions where they operate. Recently, EU regional policy makers have had to adjust their actions regarding regional innovation. Regional development strategies, or RIS3, were implemented in 2014 and will be adjusted for the period 2021-2027 (Bilas, 2020). Within this framework, regional policy makers in the EU were urged to adopt regional currencies policies, in order to guarantee concentration and prioritization in certain areas of smart specialization, thus leading to the growth of entrepreneurship and innovation, with the aim of promoting regional economic development (Saftescu et al., 2016, Simion, Paul and Mitroi, 2016)

That said, for Strong regions to increase their innovative performance, eventually becoming Leader regions, the results suggest that they implement measures in the variables EPO Patent Applications, SMEs with Product or Process Innovations, and Population with Tertiary Education. Regarding the EPO Patent Applications variable, it is essential that local governments support/encourage more financially higher education institutions/research centers when applying for patents (Verspagen, 2006). Universities should be able to mobilize their professors, researchers, and students to develop new products which may 


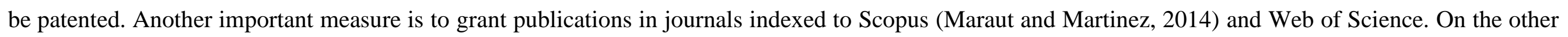

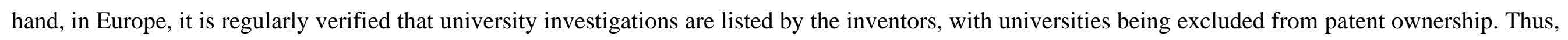

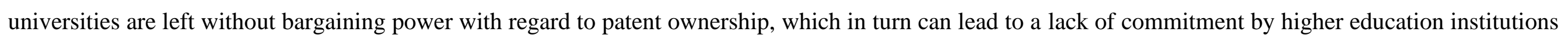

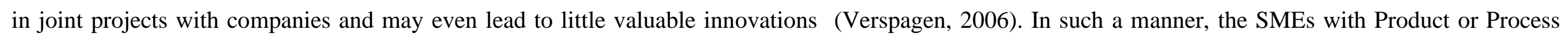

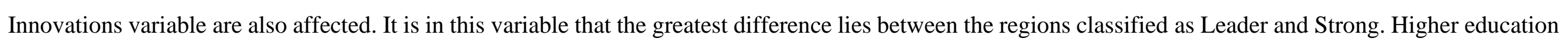

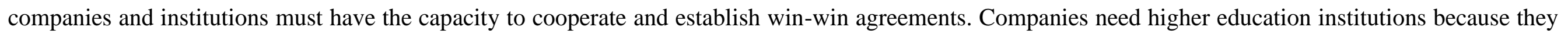

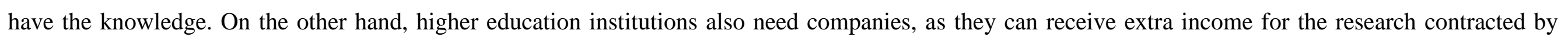

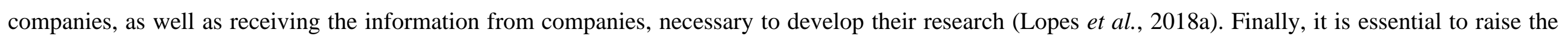

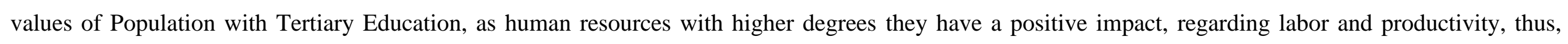

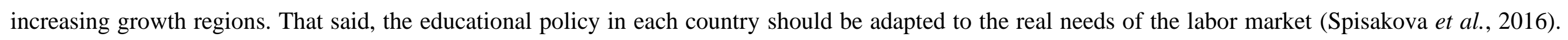

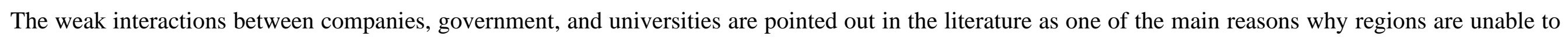
pay dividends from higher education and R\&D activities (Sterlacchini, 2008).

For Moderate regions to increase their innovative performance, and possibly becoming Strong regions, the results suggest that they should implement

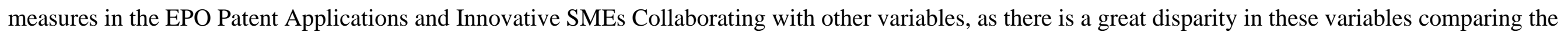

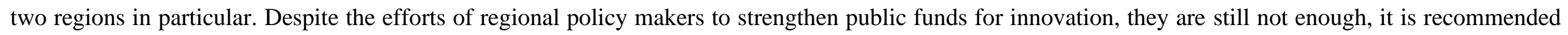

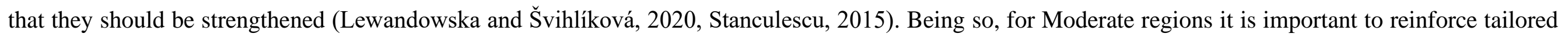

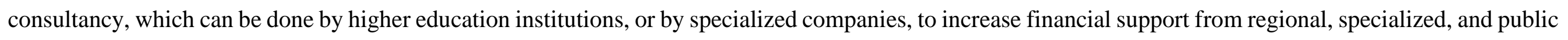

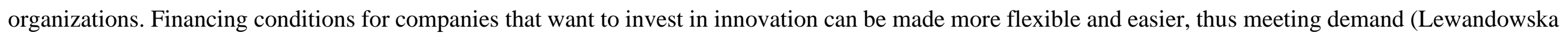

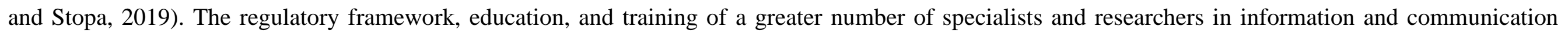

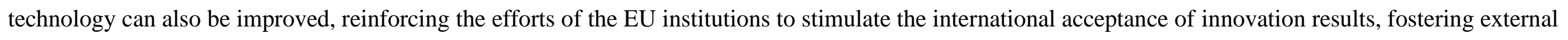

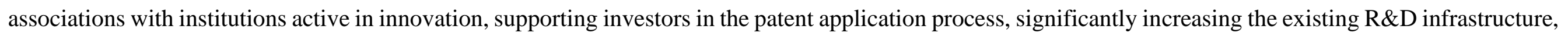

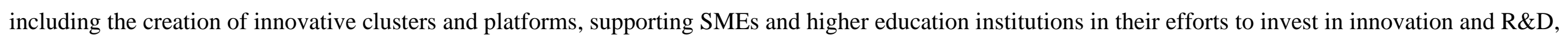
creation of clusters and innovative platforms to strengthen the connection between companies and higher education institutions (Stanculescu, 2015).

In summary, according to Ponsiglione, Quinto and Zollo (2018) the relevant factors that affect the regional innovation capacity, and differentiate the

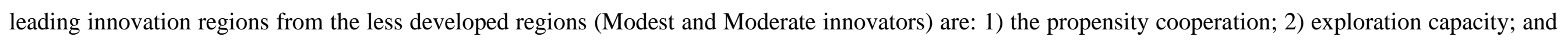
competence. These three factors can contribute to reduce the disparities between European regions with regard to the performance of innovation.

The present research is original, pertinent and clearly identifies which variables are most relevant to the classification considering the regional innovation

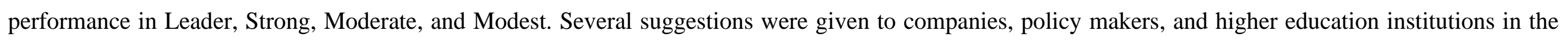

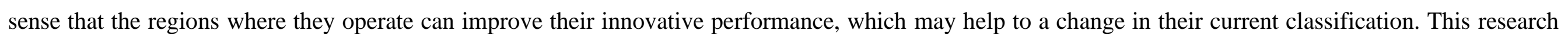
also contributes to a better understanding of the Regional Innovation Scoreboard, as well as clarifying the current literature on the subject under study. 


\subsection{Research limitations and future lines of investigation}

With regards to limitations, primarily, the paper only covers the data from countries/regions present in RIS 2016 and new data are available every year. These data are from EU countries/regions and some countries in the vicinity. Having only data from countries in Europe, it is not possible to carry out an analysis on a global level.

Secondly, the paper covers data from a pre-pandemic context, and probably the results will be different as the pandemic deaccelerates, we cannot stop seeing the emergence of regional and local economies where small geographical and political areas will try to be independent economically withing several sectors (Samarathunga and Weerathunga, 2020). Furthermore, as countries and regions start looking into reopening the economy, guide decisions not only give the pace of lifting mitigation policies but also leverage other measures that may be needed to restore confidence and trust for people to return to pre-COVID-19 behaviors (Chen, Igan, Pierri and Presbitero, 2020). Afar from the immediate crisis response, policymakers will also have to think about sustained measures after the epidemic subsides. What kind of measures will be needed to reboot the economy and ranks in the regions? This is not only a local question for the EU but also for the global economy, as different parts of the world might be in different phases of fighting the virus (Demertzis, Sapir, Tagliapietra and Wolff, 2020).

As for future lines of research after the pandemic, we suggest that qualitative data on policy actions and performance of EU Member States should be collected, with the aim of identifying best practices on innovation, consequently contributing to the development of increasingly intelligent, more intelligent, sustainable policies and greens. Comparative studies can be made between the different years of the RIS. It should be noted that as of RIS 2017 , new variables were inserted in the RIS, as previously indicated in the present study, and it is pertinent to investigate these new variables and verify their impact on the measurement of the innovative performance of the regions and what are their practical effects.

\section{References}

Arbolino, R., Boffardi, R. and De Simone, L. (2019), "Which are the Factors Influencing Innovation Performances? Evidence from Italian Cohesion Policy". Social Indicators Research, Vol. 146 No. 1, pp. 221-247.

Asheim, B. T. and Coenen, L. (2005), "Knowledge bases and regional innovation systems: Comparing Nordic clusters". Research Policy, Vol. 34 No. 8 , pp. 1173-1190.

Becheikh, N., Landry, R. and Amara, N. (2006), "Lessons from innovation empirical studies in the manufacturing sector: A systematic review of the literature from 1993-2003". Technovation, Vol. 26 No. 5-6, pp. 644-664.

Bilas, V. (2020), "Smart Specialisation Concept as a Tool for Improving Innovation Performance of the European Union Member States". Ekonomski Vjesnik, Vol. 33 No. 1, pp. 217-226.

Chen, S., Igan, D., Pierri, N. and Presbitero, A. F. 2020. Tracking the Economic Impact of COVID-19 and Mitigation Policies in Europe and the United States. Washington, D.C: International Monetary Fund.

Cooke, P. (1992), "Regional innovation systems: Competitive regulation in the new Europe". Geoforum, Vol. 23 No. 3 , pp. $365-382$.

Cooke, P., Uranga, M. G. and Etxebarria, G. (1997), "Regional innovation systems: Institutional and organisational dimensions". Research Policy, Vol. 26 No. 4-5, pp. 475-491.

Costa, J. (2020), "Why Do Publicly Funded Firms Find the University More Useful to Innovate Than Others? Can We Accomplish the RIS3 Target?". In FARINHA, L., SANTOS, D., FERREIRA, J. J. \& RANGA, M. (eds.) Regional Helix Ecosystems and Sustainable Growth: The Interaction of Innovation, Entrepreneurship and Technology Transfer. Cham, Springer International Publishing.

Creswell, J. W. (1994), Research design: Qualitative \& quantitative approaches, Thousand Oaks, CA, US, Sage Publications, Inc.

Delgado-Márquez, B. L. and García-Velasco, M. (2018), "Geographical Distribution of the European Knowledge Base Through the Lens of a Synthetic Index". Social Indicators Research, Vol. 136 No. 2, pp. 477-496. 


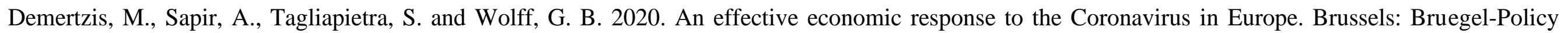
Contributions.

Doloreux, D. (2011), "Regional Innovation Systems in the Periphery: The Case of the Beauce in QuÉbec (Canada)". International Journal of Innovation Management, Vol. 07 No. 01, pp. 67-94.

Dziallas, M. and Blind, K. (2019), "Innovation indicators throughout the innovation process: An extensive literature analysis". Technovation, Vol. 80-81 No. pp. 3-29.

Fagerberg, J. (2003), "The Associational Economy: Firms, Regions and Innovation". Research Policy, Vol. 32 No. 6, pp. $1146-1148$.

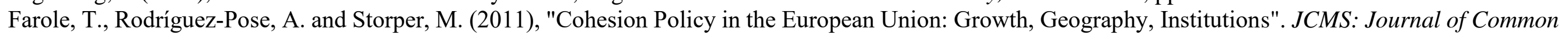
Market Studies, Vol. 49 No. 5, pp. 1089-1111.

Garcia-Bernabeu, A., Cabello, J. M. and Ruiz, F. (2020), "A Multi-Criteria Reference Point Based Approach for Assessing Regional Innovation Performance in Spain". Mathematics, Vol. 8 No. 5, pp.

Georghiou, L. (1993), "National Systems of Innovation. Towards a Theory of Innovation and Interactive Learningedited by Bengt-Ake Lundvall". Prometheus, Vol. 11 No. 2, pp. 291-291.

Hajek, P. and Henriques, R. (2017), "Modelling innovation performance of European regions using multi-output neural networks". PLoS One, Vol. 12 No. 10, pp. $1-21$.

Iammarino, S. (2018), "FDI and regional development policy". Journal of International Business Policy, Vol. 1 No. 3, pp. 157-183.

Kijek, T. and Matras-Bolibok, A. (2019), "The relationship between TFP and innovation performance: evidence from EU regions". Equilibrium-Quarterly Journal of Economics and Economic Policy, Vol. 14 No. 4, pp. 695-709.

Landabaso, M. (2014), "Guest editorial on research and innovation strategies for smart specialisation in Europe: Theory and practice of new innovation policy approaches". European Journal of Innovation Management, Vol. 17 No. 4, pp. 378-389.

Lewandowska, A. and Stopa, M. (2019), "Do SME's innovation strategies influence their effectiveness of innovation? Some evidence from the case of Podkarpackie as peripheral region in Poland". Equilibrium, Vol. 14 No. 3, pp. 521-536.

Lewandowska, A. and Švihlíková, I. (2020), "Regional Innovation System in the Podkarpackie against selected Polish and EU regions". Journal of International Studies, Vol. 13 No. 2, pp. 212-223.

Leydesdorff, L. and Fritsch, M. (2006), "Measuring the knowledge base of regional innovation systems in Germany in terms of a Triple Helix dynamics". Research Policy, Vol. 35 No. 10, pp. 1538-1553.

Lopes, J., Farinha, L., Ferreira, J. J. and Ferreira, F. (2018a), "Peeking beyond the wall: analysing university technology transfer and commercialisation processes". International Journal of Technology Management, Vol. 78 No. 1-2, pp. 107-132.

Lopes, J., Farinha, L., Ferreira, J. J. and Silveira, P. (2018b), "Smart specialization policies: innovative performance models from European regions". European Planning Studies, Vol. 26 No. 11, pp. 2114-2124.

Lopes, J., Farinha, L. and Ferreira, J. J. M. (2019a), "Reflecting on the innovative performances of European regions in the age of smart specialisation". Global Business and Economics Review, Vol. 21 No. 5, pp. 605-623.

Lopes, J., Ferreira, J. J. and Farinha, L. (2019b), "Innovation strategies for smart specialisation (RIS3): Past, present and future research". Growth and Change, Vol. 50 No. 1, pp. 38-68.

Lopes, J. and Franco, M. (2019), "Review About Regional Development Networks: an Ecosystem Model Proposal". Journal of the Knowledge Economy, Vol. 10 No. 1 , pp. $275-297$.

Lundvall, B. A. (2007), "National Innovation Systems-Analytical Concept and Development Tool". Industry and Innovation, Vol. 14 No. 1, pp. 95-119.

Maraut, S. and Martinez, C. (2014), "Identifying author-inventors from Spain: methods and a first insight into results". Scientometrics, Vol. 101 No. 1, pp. 445476.

Marôco, J. (2018), Análise Estatística com o SPSS Statistics ( $7^{a}$ Edição), Portugal, ReportNumber, Lda.

Mccann, P. and Ortega-Argiles, R. (2015), "Smart Specialization, Regional Growth and Applications to European Union Cohesion Policy". Regional Studies, Vol. 49 No. 8, pp. 1291-1302.

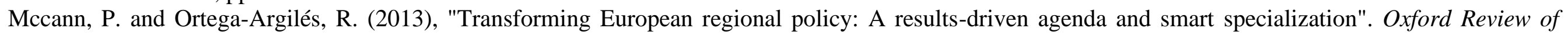
Economic Policy, Vol. 29 No. 2, pp. 405-431.

Mills, G. E. and Gay, L. R. (2019), Educational research : competencies for analysis and applications, New York, USA, Pearson.

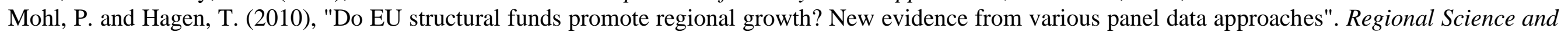
Urban Economics, Vol. 40 No. 5, pp. 353-365. 


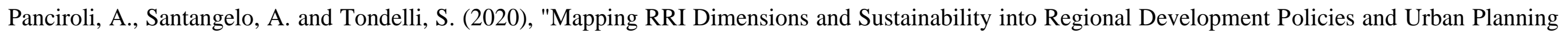
Instruments". Sustainability, Vol. 12 No. 14, pp. 5675.

Ponsiglione, C., Quinto, I. and Zollo, G. (2018), "Regional Innovation Systems as Complex Adaptive Systems: The Case of Lagging European Regions". Sustainability, Vol. 10 No. 8, pp. 2862.

Rentková, K. (2018), "Regional Innovation Strategies Applied in Slovak Republic". SSRN Electronic Journal, Vol. 4 No. 1 , pp. $320-326$.

Ris 2016. Regional Innovation Scoreboard 2016. Brussels, Belgium: European Commission. Retrieved from https://op.europa.eu/s/oofu (26/06/2018).

Sabatino, M. and Talamo, G. (2017), "Innovation and Competitiveness of European Regions". Research in Applied Economics, Vol. 9 No. 3 , pp. 45.

Saftescu, R., Simion, E., Paul, C. and Mitroi, M. (2016), "Governance of Smart Specialisation: Experiences of Four European Regions". Europolity-Continuity and Change in European Governance, Vol. 10 No. 2, pp. 247-263.

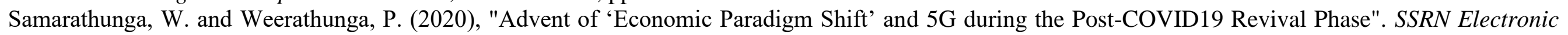
Journal, Vol. No. pp.

Spisakova, E. D., Gontkovicova, B. and Hajduova, Z. (2016), "Education from the perspective of the Europe 2020 strategy: the case of southern countries of the European Union". Economics \& Sociology, Vol. 9 No. 2, pp. 266-278.

Stanculescu, E. P. (2015), "European Union: Innovation Activity and Competitiveness. Realities and Perspectives". Global Economic Observer, Vol. 3 No. 1, pp. 4-9.

Stejskal, J. (2009), Regionální politika a její nástroje / Jan Stejskal, Jaroslav Kovárník, Praha, Portál.

Sterlacchini, A. (2008), "R\&D, higher education and regional growth: Uneven linkages among European regions". Research Policy, Vol. 37 No. 6-7, pp. 10961107.

Stimson, R. J., Stough, R. R. and Salazar, M. (2005), "Leadership and institutional factors in endogenous regional economic development". Investigaciones Regionales-Journal of Regional Research, Vol. No. 7, pp. 23-52.

Surubaru, N.-C. (2017), "Administrative capacity or quality of political governance? EU Cohesion Policy in the new Europe, 2007-13". Regional Studies, Vol. 51 No. 6, pp. 844-856.

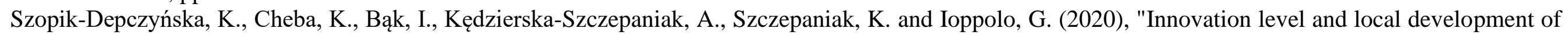
EU regions. A new assessment approach". Land Use Policy, Vol. 99 No. pp. 1-11.

Tiits, M., Kalvet, T. and Muerk, I. (2015), "Smart Specialisation in Cohesion Economies". Journal of the Knowledge Economy, Vol. 6 No. 2, pp. 296-319.

Verspagen, B. (2006), "University research, intellectual property rights and european innovation systems". Journal of Economic Surveys, Vol. 20 No. 4, pp. 607632.

Wamser, G., Nam, C. W. and Schoenberg, A. (2013), "The Lisbon Agenda and Innovation-oriented Cohesion Policy: A New Challenge for Economic Integration among the EU Regions". Journal of Economic Integration, Vol. 28 No. 1, pp. 37-58.

Xiao, Z., Du, X. and Wu, C. (2017), "Regional difference and evolution and convergence of innovation capability in China: Research on space and factorial levels". Sustainability, Vol. 9 No. 9, pp. 1644.

Yilmaz, K. (2013), "Comparison of Quantitative and Qualitative Research Traditions: epistemological, theoretical, and methodological differences". European Journal of Education, Vol. 48 No. 2, pp. 311-325.

Zdražil, P. and Applová, P. (2016), "Growth disparities among regions of the visegrad group countries: An evidence of their extent and nature". E a M: Ekonomie a Management, Vol. 19 No. 2, pp. 37-54. 